\title{
Anotações sobre aspectos temáticos e contextuais da violência: vetores sugestivos
}

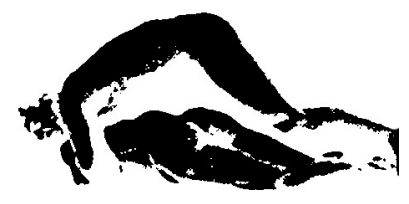

José Carlos de Paula Carvalho ${ }^{1}$

O fenômeno (as manifestações) e a instituição (os institutos, as regras canalizando institucionalmente a agressividade através de "confrarias") do trote fazem ressaltar uma rica problemática quando considerados sob a ótica da "violência originária" e da "destrudo", do "imaginário do anômico / a-estrutural", dos "ritos de iniciação" e suas "transferências míticas" no "liminóide" dos "rituais de rebelião"/ "rituais de inversão", todos eles fatores que emergem numa "sociedade urbano-industrial" que, por ter perdido as instituições e o espaldar da "tradição" das sociedades "arcaicas", instaurando-se o "vazio institucional", apresenta-se como uma "heterocultura" e um "bricolage", por onde, nessa atmosfera de "desencantamento de mundo", irrompem a "Sombra Coletiva" e o pano de fundo mais amplo da "problemática do Mal". Alguns pontos merecem ser repensados na dinâmica violência / agressividade / destrudo / iniciação / trote...ecologia mental da angústia $e$ da morte / problemática do Mal / Sombra Coletiva...corporeidade.

1 Eliade mostrou que a iniciação é uma "mutação ontológica de estado / estatuto", destacando-se sobretudo os "ritos de iniciação da puberdade e da adolescência" ao estado adulto; nas sociedades tradicionais são os ritos de iniciação que regulam a dinâmica sócio-psico-organizacional, aqui no caso das "classes de idades"; mas têm a sustentá-los todo o respaldo de uma "metafísica sócio-cultural", que canaliza de modo construtivo a agressividade e a violência, precisamente através daquilo que, dentre outros, Zahan e Erny chamaram de "sociedades ou confrarias iniciáticas" e "pedagogias iniciáticas".

\footnotetext{
${ }^{1}$ Filósofo e Antropólogo, professor da Faculdade de Educação da Universidade de São Paulo. Coordendor de Projeto Integrado Interinstitucional "Violência, imaginário e educação", FEUSP/CNPq.
} 
Se os "ritos de passagem" (Van Gennep), de um a outro estado, comportam "provas / provações", "feridas simbólicas / feridas reais e mutilações / cicatrizes e a morte", eventualmente, o advento dessa morte eventual é provido de Sentido, pois as sociedades arcaicas dispõem de uma "pedagogia da morte", como mostrou Thomas. Há, portanto, uma coerência simbólica de ação nessas "sociedades holistas"(Dumont). Entretanto, nas "sociedades urbano-industriais", com a laicização, as "religiões políticas” (Aron) e a instauração do "projeto de Entzauberung" ("desencantamento de mundo") - advindo com o "espírito do capitalismo" e suas "racionalizações" em nível de economia, de sociedade (burocratização da vida social), de cultura e de personalidade, como com Max Weber salientou Habermas, essa "unidimensionalização do homem" proscreve a tradição e a afetividade como orientação da ação social, pois juntamente com a organização racional do trabalho acontecem as "racionalizações secundarizantes". Estas que a psicanálise de Freud mostrou na construção repressiva da cultura, aliás construção de Thanatos ou pulsão de morte, a que Róheim, com a "teoria do trauma ontogenético nas origens da cultura", deu magníficos desenvolvimentos -, de certo modo aliado ao "projeto iluminista" da DeusaRazão e dos direitos humanos e de cidadania, nessa atmosfera de exorcismo da sensibilidade, da paixão, do alógico, de pathos e pothos...pelo espírito prometeico-fáustico que então canalizava a agressividade e a violência no sentido da construção do capitalismo, do homem burguês e das "experiências burguesas". Enquanto se acreditou - antes da Decadência "finde-siècle", a Sombra Coletiva da então Modernidade - na "primavera industrial", agressividade e violência foram "canalizadas" produtivamente (vale dizer, o "princípio do prazer" foi substituído não só pelo "princípio de realidade", mas numa confusão ideológica entre razão e racionalismo, entre razão técnica e razão política, mostraram Marcuse e Morin, tornou-se a realidade no "princípio do rendimento") e quando explodiam ou ameaçavam explodir às margens e nos interstícios, como nos "duelos estudantis" e no instituto do Mensur, eram canalizados - mas não sem dificuldades... - nas confrarias estudantis que "cultivavam o ódio" e "acariciavam as cicatrizes" como viáticos da experiência burguesa de ascensão social e "paginação" (Le Goff) da "destrudo" (Weiss). Perdêramos, entretanto, o respaldo das pedagogias iniciáticas e das pedagogias da morte (agressividade e violência), da agressividade violenta, das provações, da purificação moral, da guerra, do sentido educativo (pedagogos como Paulsen, teólogos como Harnack etc.) contido no Mensur... mas experiência vivida também da ética do companheirismo e da intimidade, do "tribalismo" contido nesses institutos. Remetemos o leitor ao indispensável texto de Peter Gay, "O Cultivo do Ódio". Diz o autor:

Ao oferecer camaradagem e ocasiões para regressões coletivas, os Corps e as Burschenschaften funcionavam como antídotos para a ansiedade adolescente, a solidão, e muitas vezes o isolamento asssustador, e como alívio para os estudos, vistos como uma disciplina árida e repetitiva...A adolescência, na moderna cultura de classe média, com certeza, é uma época tempestuosa, excitante e 
excitada. É tempo de testes e de experimentação, um tempo que volta a encenar os dramas e revive as paixões infantis. Os sentimentos sexuais agressivos que a criança aprendeu a encarar como impróprios e perversos, sentimentos que são colocados além da consciência, agora retornam, quase literalmente com uma vingança. O comportamento expressivo, desajeitado, violento, muitas vezes irracional, dirigido contra todos, inclusive contra si mesmo, parece menos uma escolha do que um destino. A maturação fisiológica permite que as fantasias de triunfos sexuais passem de fúteis e vagos sonhos a possibilidades precisas $e$ acessíveis. O mesmo é verdade para a agressão: a rebelião contra a autoridade paterna, impossível, quase impensável, nos anos infantis, agora parece estar ao alcance do adolescente. Mas as visões grandiosas de onipotência e de supremacia são sombreadas pelo assustador pesadelo do fiasco. E assim as novas forças do adolescente se tornam uma fonte de conflitos e de ansiedades, bem como o desejo de reter objetos de amor infantil teimosamente se confronta com o desejo de se livrar deles, e a agressão é tecida na textura de florescentes fantasias sexuais...Dessa perspectiva o Mensur parece ter sido brilhantemente concebido para enfrentar as devastações da puberdade. Sem dúvida, até mesmo na Alemanha, a grande maioria das pessoas, homens e mulheres, tinha de atravessar o campo minado da adolescência sem o benefício de um duelo ritual. Mas então outros ritos de passagem estavam à sua espera, na escola, na família, nas ruas. E muitos desses ritos, fossem eles provas engenhosamente elaboradas ou trotes violentos, eram exercícios de rara crueldade impostos ao aspirante a adulto, justificados aos olhos dos que os infligiam como necessários passos através da fronteira da maturidade...Melhor ainda, o Mensur e seus substitutivos infligia dor suficiente para gratificar o mais exigente superego...O Mensur era a codificação da adolescência; era um caminho - não o único, ou o melhorpara que certos burgueses do séc.XIX regulassem suas agressões. Não chegava a ser uma receita para a maturidade pessoal ou política. Mais do que a maioria dos arranjos sociais que disciplinavam a belicosidade, o Mensur era paradoxal e imensamente instrutivo, nas maneiras contraditórias de cultivar o ódio. Elaborado para conter o espírito de agressividade, estimulava tal espírito: controlava a violência e canonizava-a. (Gay, 1995, p.39-41)

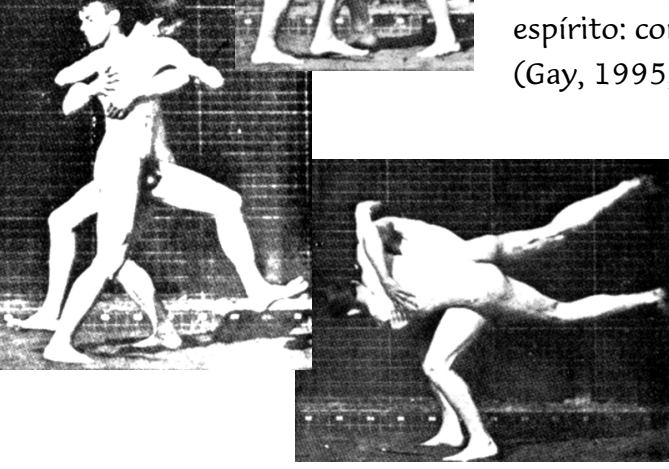


2 Nesse vetor de engendramento da Modernidade/Decadência em seus institutos sobre a agressividade / violência, como nos defrontamos com as ritológicas da pós-modernidade nos âmbitos da cultura, da escola e da profissão?

Com a psicanálise, estabelece-se o nível fundacional da cultura através do id num processo de sublimação repressiva - tão bem contextualizado contemporaneamente por Marcuse em "Eros e Civilização"- levada a cabo pelo superego; entretanto, nessa anamorfose Freud reconhece a ambivalência de todo o processo ao supor, e cada vez mais vinculá-lo, à ação da pulsão de morte ou Thanatos como princípio, de tal modo que, opondose à pulsão de vida ou Eros ou libido, configura-se aquilo que Weiss designou como destrudo, ou seja, o instinto de morte que estrutura a cultura, e a sociedade e sua ação, como instinto de agressividade e de morte através das formações reativas, como precisou também Róheim. Destarte, com Klein, com Róheim, amor e ódio estão mesclados e, por um lado, respondem pelo caráter de instauração violenta originária (violência originária) da sociedade e da cultura, e de seu caráter tanático (agressivo e mortífero) e entrópico e, por outro lado, mostram como não se pode esquivar à essa ambivalência da violência originária por meio de uma supersocialização do homem (Wrong), como pretende o oponente "projeto iluminista", pois a acolhida e o reconhecimento dessa destrudo apresenta propriedades verdadeiramente evolucionárias para o homem. Assim como Brown destacou no livro "Vidas contra a morte": o escândalo é a luta da vida contra a morte, pois o universo é entrópico e a instauração da sociedade e da cultura não pode elidir a presença da destrudo, da violência originária ou "essencial" (Girard), portanto da agressividade e da violência e da morte, em suma conectadas no instinto de dominação, reconhecido como um dos motores da realização das injunções do "espírito do capitalismo" (seja voltado para a agressão pelo controle da Natureza, seja do Homem, seja pela realização do trabalho competitivo). E tudo isso é regido por Thanatos ou pela pulsão de morte e pelo comportamento agressivo. Reconhece-se, portanto, como ineludível no âmago da cultura e das organizações sociais $e$ grupais, nas atividades e produções, a "presença de uma capacidade de ser agressivo", como diz Sandler, funcionando "em diversas circunstâncias, mobilizada por qualquer coisa desagradável experimentada, seja ela pressão externa ou impulso interno" (Gay, p.535).

No âmbito da organização da Cidade, a história comparada da ideologia tripartida dos indo-europeus, obra magistral de Dumézil, dentre as funções organizatórias da sociabilidade e das "ordens", viria reconhecer também a ineludível função guerreira ou marcial...; um dos fundadores da moderna sociologia das organizações, Pareto reconhecia na estruturação social uma dinâmica como embate entre as classes das persistências ou das conservações e a classe da adaptação ou instinto de combinação, ligando as primeiras ao embate pelo "território" como função predatória / estruturas de defesa e ataque e como função produtiva / estruturas de elaboração e cultura dos alimentos, ambas entretanto vinculadas ao já referido instinto de dominação. Trata-se, portanto, do estabelecimento de uma polemologia ineludivel no âmago da natureza humana: a guerra (e 
${ }^{2}$ Encontramoso grupo do devaneio muscular ou da myopsyche, nos "vandalismos" de adolescentes do Colegial da EEPSG. João Pedro Ferraz/Ibirá/SP, ou imaginário da errância e digressão desordenada; o imaginário da derrelição e o imaginário da diabolética, respectivamente nos mesmos grupos etários do Liceu Pasteur/SP e do Colégio Iavne-Beith Chinuch/SP, textos aos quais remetemos o leitor, pois será um dos públicos de calouros-e de futuros veteranos...-a ingressarem sobretudo em Medicina,

Engenharia e Direito, cujas "paisagens mentais"assim levantamos "de dentro" e "de fora" das instituições e institutos-regras. portanto a agressividade, a violência, a angústia, a morte, a dominação...) é a mãe de todas as coisas, como longínquamente falara Heráclito.

Biologicamente duas descobertas viriam dar prolongamentos e saturação "positiva" a tais posições: de modo ambivalente, a fetalização ou neotenia humana, como veremos; e bem próximo da "revolução biológica", que aqui não trataremos, a descoberta do triunic brain (MacLean, Laborit) e suas implicações, sobretudo do "sistema límbico"- que faz a dinâmica do Inconsciente e de seus princípios adentrarem, estruturando, as relações vinculares pessoais e societais através daquilo que Morin chamou de disrupção afetiva e agressiva, que se torna o fundamento do homo demens e do homo violens, que também somos.

A neotenia humana ou juvenilização é um processo hipercomplexo (Morin). Lorenz e Gehlen ensinam-nos que o homem é um ser aberto para o mundo (a busca da ampliação do espaço stenoecético), um especialista da nãoespecialização, um aprendiz por curiosidade ativa, um lúdico-explorador, um ser permanentemente incompleto e inacabado, portanto, um ser do acaso, da álea, do risco, do perigo (da periclitação), da desordem complexificante, ser ambígüo, ambivalente e crísico, em busca da antropolítica da neg-entropia (da libido e de Eros), mas que irá se defrontar com a antropolítica entrópica na vida bio-psico-social e na educação (porque aqui, com a neotenia, só é compatível uma educação negativa ou contra-educação e um imaginário do conflito e da ruptura pela busca de conteúdos não dados por uma educação reprodutora ou "praxeológica" estribada num imaginário da ordem e da segurança e estribados no instinto de dominação), que irá portanto enfrentar, de início fora, o impacto com a destrudo civilizacional, e posteriormente intragrupo, como portadores que seus membros são da Sombra Coletiva... portanto potenciais "bodes expiatórios" do coletivo da ordem, pois são acuados a serem "ovelhas negras". Poderemos ver na antropolítica da counter-culture como isso se deu, em termos sócio-culturais e educativos, sobretudo porque tendo a ver não só com a educabilidade e a sociabilidade, mas com a educação e a escola, pois foram "revoltas estudantis como rituais coletivos de iniciação à uma outra maturidade". Mas é importante que se destaque, desde já, e mais uma vez, que a cenarização mítico-ritual, em ambas as perspectivações, presentificou... a violência originária irredutivel, mesmo no "modelo da comunidade". Ao mesmo tempo poderemos ver como, a partir de então, desponta uma teoria da crise e uma teoria da anomia, que nos levarão de imediato para as características da atual sociedade $e$ cultura, e culturas escolares e profissionais, da pós-modernidade. Estudamos desde 1982 essa totalização sócio-cultural e grupal como imaginário do a-estrutural e do anômico, tendo identificado as categorias do comportamento organizacional alternativo e tendo estudado a presentificação desse universo da angústia em várias escolas, na esteira de Projetos Integrados, onde sempre se associa à presença da violência e da agressividade ${ }^{2}$, da angústia, da ansiedade, do medo ... e do pânico... envolvendo muitas vezes não "a evitação", mas o enfrentamento angustiado (por exemplo, com as gangues de skin-heads, de "meninos de rua", de "galeras"...).

3 Desde meados das décadas de 60 à de 70 assistimos aos movimentos 


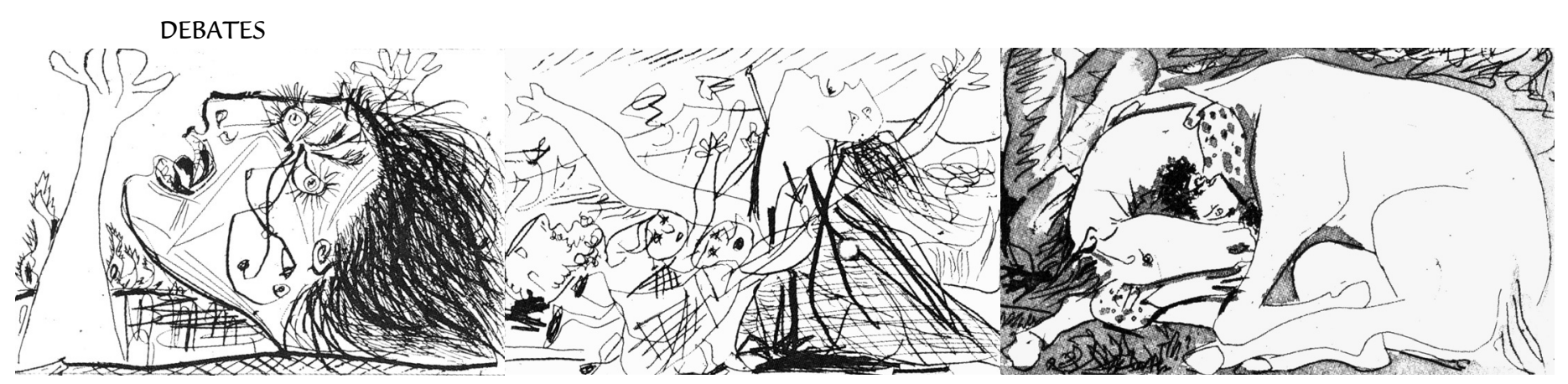

PICASSO, Sonho e mentira de Franco, 1937

contra-culturais e à gestação do que seria a heterocultura (Poirier) pósmoderna, uma hibridação entre matrizes sócio-culturais e psicoorganizacionais, educativas, provenientes da modernidade, e seus imperativos produtivistas, $e$ as matrizes emergentes como pseudomorfoses (Spengler) da tradição, com os "retornos" cíclicos (riccorsi de Vico). Vimos se constituirem uma sociedade e uma cultura, com suas instituições, pulverizadas; assistimos à proliferação do neo-tribalismo (Maffesoli) apoiando-se nos fenômenos dos bandos de adolescentes estudados por Niederhoffer-Bloch - com seus rituais de iniciação à inacabada maturidade $e$ à entrada na vida (Lapassade) - e, mais em profundidade, tendo como base a "ontogenia da ritualização de passagem" estudada por Erikson, em suas dimensões sócio-biológicas, psico-culturais e educativo-organizacionais através do processo de especiação ${ }^{3}$ onde a escola é a unidade de base, segundo Erikson. Estudos vários (Rodrigues de Lima, Braun Mont’Alverne, Itmann...) mostraram a proxêmica (o espaço físico e o espaço mental) da escola como tendo assim se transformado num cenário mítico-ritual agenciando uma corporeidade outra / uma corporação outra numa nova ecologia mental através de processos e rituais de passagem dos intragrupos e inter-grupos, das classes de idade sobretudo (daí as provas, exames, os trotes) de que o funcionamento da escola apresentado por Bourdieu ilustra tão bem o caráter laico-probatório e a conjugação entre violência física e violência simbólica, através das provas, exames...trotes. Mas nessas novas matrizes pseudo-especiatórias ou tribais de ritos de iniciação à tradição modernosa ou à modernidade tradicional, com os ritos de passagem e a liminaridade para a pertença, encontramos a mais ampla contextualização dessa "pseudo-espécie" chamada escola, com suas "tribos", nas molduras mais amplamente compreensivas da liminaridade (Turner e Gluckman) e da anomia (Duvignaud e Bourdin) da sociedade em mosaico (Lacroix), onde o vazio institucional (Lewin e Bourdin) permite que, através dos ritos de passagem como liminaridade (ritos de inversão e ritos de rebelião), na escola como em seus intra-grupos "tribos", venha se liberar a destrudo e a gama de agressividade, violência e desordem que consigo ela carreia, de tal modo que os "templos de cultura" se tornam cenários míticorituais para catarse das formas da destrudo, fundamentalmente marcadas nos momentos, nos ritos e nas cerimônias de passagem...da adolescência caloura à maturidade veterana. Especifiquemos alguns pontos, retomando trechos que já dissemos alhures:

A anomia, conforme os trabalhos de Lacroix, situa-se nas molduras

\footnotetext{
${ }^{3}$ A constituição sóciocultural de "pseudoespécies" equivalentes às biológicas, com as propriedades de criação de um peculiar estilo de seleção e admissão baseado no enclausuramento, nos mecanismos de defesa do "in-group" como membro e de exclusão através das "estratégias do preconceito" (Taguieff: antropofagia $e$ antropoemia) dos considerados "outgroup", numa produção, portanto, de alteridades e de outros; o acesso será tanto mais probabatório e permeado de violência, assim como a luta contra "os outros", quanto mais prestigiosa for a "pseudo-espécie"/ tribo / grupo / bando / gangue etc. e tanto maior for o "vazio institucional".
} 
de uma teoria da crise, que também é uma teoria do Estado - os momentos de efervescência criadora escandem a história das sociedades-, e fundamentalmente de crise da centralidade social, a qual se dilui sob a ação de dois processos complementares: um de dispersão - o processo que Moles e MacLuhan chamaram de “organização da cultura de mosaico"- e outro de dilatação - a lógica hipocomplexa da homogeneização ou o processo de inflação $e$ turgescência das sociedades afluentes, descritos por Touraine e por Baudrillard. Nesse sentido, “a anomia caracteriza uma forma, e a fundamental no plano das representações, de criatividade social. Implica um triplo movimento de desvendamento com relação ao que as instituições, os valores e as imagens procuram mascarar, de subversão desses modelos pelo comportamento ou a expressão, de livre invenção, de "bricolage", de criação por ensaio e por erro. Tal forma ou dimensão das crises concerne o centro. São as encruzilhadas da cultura e da ação que são questionadas: ideologias, valores, normas e modos de comunicação. E a anomia só se desenvolve plenamente conquistando o centro por uma generalização das manifestações periféricas "..." A anomia refere-se a uma crise de implosão... afeta o sentido dos atos, sentido esse que deixa de aparecer com clareza; torna impossível a previsão do comportamento de outrem, de que não se sabe mais que esperar; ela despolariza as relações sociais; as hierarquias, as posições e as redes de relações tornam-se instáveis ou inapreensíveis... A anomia provoca a emergência individual e pseudo-especiatória ("tribal”/ grupal) do recalcado e do não-dito, tratando-se, entretanto, do recalcado fundamental, ou seja, de questões que, formuladas, para elas não temos respostas e que, aos poucos, são submetidas ao trabalho da denegação ideológica...

(Paula Carvalho, 1990, p.122-3)

Portanto a anomia é ambivalente, pois propicia o vazio institucional "ausência generalizada de pontos de referência e de perspectiva...é desordem instituída, essencialmente periférica, na medida em que, mesmo em se podendo tornar um perigo para o centro na eventualidade de se ampliar a toda uma instituição, não acarreta necessariamente a comunicação, mais se afastando dos centros do que visando a atingi-los" (idem, p.125) - e a implosão da destrudo. Mas é também um viático de contestação/revelação das disfunções e disnomias de uma sociedade e de uma cultura e, assim, por exemplo, através da liminaridade e seu modelo de "communitas", dos rituais de inversão e de rebelião, pode provocar as instituições a falarem o não-dito, tendo assim o efeito de engendrar a dissidência libidinal e, em termos de análise institucional e de pedagogia implicativa (Lapassade, Lourau, Hess), dizemos que ela tem um efeito analisador. Entretanto, como historicamente mostrou de sobejo a contracultura, mesmo nesses casos, foram ativadas a violência $e$ a agressividade, ainda que como defesas contra a agressão do poder externo $e$ estatal...Portanto, mesmo em seu bifrontalismo, o imaginário do anômico $e$ 
a-estrutural secreta a violência, a agressão, a angústia...sobretudo porque advindo numa sociedade pulverizada onde a orientação é atribuída, é rateada entre as "pseudo-espécies" ("tribos", bandos, gangues) de que, lembremos, segundo Erikson, a escola é o modelo / campo exemplar. Nesse momento de perda da totalização, as tribos fazem suas leis...numa atmosfera de anomia e de vazio institucional e, junto à arbitrariedade tanatocrática da cultura alimentada pela destrudo e por Thanatos, potencia-se essa arbitrariedade intra-grupos e inter-grupos na luta pela validação única e excluinte dos códigos tribais como normas "universais": a ação desencadeada é arbitrariamente potenciada pela conjunção entre o autoritarismo e a arbitrariedade, contidos no instinto ou pulsão de dominação, que vimos ser uma das expressões da pulsão de morte. Como então, nesse universo da entropia positiva, da dominação tanatocrática, da reprodução autoritária ou das personalidades anômicas, dos grupos como "tribos", em suma, como nesse universo de angústia e de paisagem mental de morte escandalizar-se com a violência originária emergente num trote? Como esperar aqui uma autoregulação outra, por Eros e pela pulsão de vida, que é aquilo a que visam as "boas intenções" do "projeto iluminista" através da constituição da cidadania? Como afirma Morin, em "O homem e a morte", nesse universo o escândalo não é a morte, o escândalo é a vida... Por isso o "projeto iluminista", ao se centrar numa "supersocialização da natureza humana", numa filosofia da consciência, da vontade e do ego, nas "religiões políticas" (Aron e Sironneau: nazismo, fascismo, stalinismo...e todas as formas de totalitarismo e fundalismo, inclusive o "fundamentalismo econômico" do Brasil atual...), pode não vir a termo com as trevas do inconsciente e da violência originária, com o Mal, contra o qual ele luta, como barbárie, ficando no domínio da própria destrudo civilizacional por inoperatividade de propostas que aprofundem a nada bela natureza humana que aqui emerge como Sombra Coletiva e retorno de Dionísio / Pã (Jung e Hillman)...

4 De um modo amplo, o estudante terá seus passos regidos pelos quadros da burocratização da vida social e por uma pedagogia burocrática (Lobrot, Ardoino, Hess), que irá regular seus fatores e modos e estilos relacionais, organizados de modo produtivo e despersonalizado. Lefebvre, no "Manifesto Diferencialista", caracteriza esse amplo quadro contextualizador de projeto de redução generalizada articulado pela razão técnica e pela racionalidade técnica e racionalização do trabalho (produtivo e competitivo), apontando-lhes os seguintes traços: redução do conhecer ao conhecimento e do conhecimento à informação (perda da formação, portanto); redução da ação e da reflexão aos esquemas operacionais (saber técnico e tecnologias); redução do possível ao provável e expurgo do imaginário e da afetividade (materialismo, agnosticismo e perda da sensibilidade, assim como da "consciência antecipativa" que provê às transformações das estruturas fantasmáticas); redução da álea, do risco, do acaso, da desordem complexificante...(neotenia "pervertida" que permite aqui adentrarem os componentes de destrudo da ação, portanto a angústia, a ansiedade, a agressividade, a violência... postas a serviço de um imaginário 
da ordem e da segurança, que garantirá o sucesso ético-político e econômico através de uma deontologia do corpo produtivo e do discurso da competência); eliminação das diferenças pela repetição (trato destratado do Outro e monotonia / unidimensionalização / homogeneização entrópica da rotina de vida e de trabalho, abrindo caminho inconsciente para as explosões destrutivas da vida nos momentos das "passagens"); articulação do projeto tecnocientífico à dominação política ( instinto de dominação $e$ agência/ agentes da tanatocracia). O estudante e o médico, nessa ampla pedagogia burocrática, tornam-se também burocratas e gestores de negócios de saúde, administradores de infortúnios para o qual não há resposta, como mostraram os estudos de Augé, de Herzlich e de Laplantine, para o problema e o sentido do Mal, que estão na origem da Medicina e no trato com os doentes. Mas esse Mal se presentifica, nas molduras civilizacionais, como presença da Morte e do Tempo, ao que se tem que reagir, defensivamente fugir por denegação... E como mostram Jaques $e$ Bastide, as instituições e os institutos são mecanismos de defesa potenciados contra tais fatores anxiógenos, vale dizer, certo conhecimento e certos procedimentos científicos são usados para introduzir um contrapeso contratransferencial à emergência dessa problemática: Devereux, em "Da angústia ao método nas ciências do comportamento", mostrou com convicção e peso como as instituições e os saberes são usados nesse sentido sob máscaras científicas, sendo um "ritual de evitação da morte", que explodirá como violência e agressividade projetada nos ritos de passagem e de adentramento de pertença que são, por exemplo, os trotes: daí a anomia $e$ a destrudo, em suma, a regência por uma deontologia denegada, $e$ portanto projetada, da morte e do poder tanatocrático. Para enfrentar esses fatores anxiógenos, e as eventuais explosões anômicas do denegado, não só os momentos dessa permissividade denegada são regulados (nos trotes, provas etc.), mas deve haver escudos mais eficientes e constantes: são eles a imagem legada do corpo produtivo e o discurso burocrático da competência. Ambos introduzem as relações impessoais e de dominação como fatores de relação... Os trabalhos de Reich (pedagogicamente desdobrados por Schmidt) mostraram, juntamente com os de Le Breton, como cada sociedade produz a imagem do corpo de que carece, e assim a imagem do corpo com a qual lidamos é uma imagem social do corpo, que é uma imagem do próprio corpo social. Mexer com a imagem do corpo é mexer com a estrutura da sociedade e da cultura. Os trabalhos posteriores de Douglas, peculiarmente interessando a biólogos e médicos, evidenciam que há uma ética social e uma deontologia (que podem ser "estratégias de preconceito"), uma moral modelando imagem do corpo como se fosse "fato biológico", na realidade sendo "coisa social"... por sob a cientificidade, um moralismo defensivo... Assim, tocar na imagem (social) do corpo é tocar na sociedade e na imagem requerida de sociedade que o engendrou; por isso os perigos e as lutas, como Laplantine evidenciou, com os sistemas de etiologia e de prognoses... Ora, sabemos, pelos trabalhos desenvolvidos, que o estudante, o professor e o médico... e o paciente (persuadido pelo discurso da competência...) recebem a imagem de um corpo produtivo, de um corpo em estase libidinal (Reich), mais regido pelas disnomias $e$ 
disfunções que põem a denegada morte como horizonte, do que a imagem de um corpo de amor, de um corpo orgástico, como se expressa Brown. E o discurso da competência (Chauí) será o veículo burocrático, despersonalizador, despótico, "sabido" (e poderoso) dessa retórica da persuasão e da inculcação... dos valores tanatocráticos, quando professores $e$ médicos se permitem o luxo de se relacionar com o estudante e com o paciente sobre suas "razões"... manifestas, porque há uma gama de "ocultas" que defensivamente permanecem na ocultação... Por isso a tendência é a de deter o "saber"... e impô-lo sob a máscara da confiança e da credulidade (não da credibilidade), mas geralmente sob a violência e agressividade de um silêncio...

\section{Referências bibliográficas}

GAY, P. A experiência burguesa, da rainha Vitória a Freud: III. O Cultivo do Ódio. São Paulo: Companhia das Letras, 1995.

PAULA CARVALHO, J.C. Antropologia das organizações e educação: um ensaio holonômico. Rio de Janeiro: Imago, 1990.
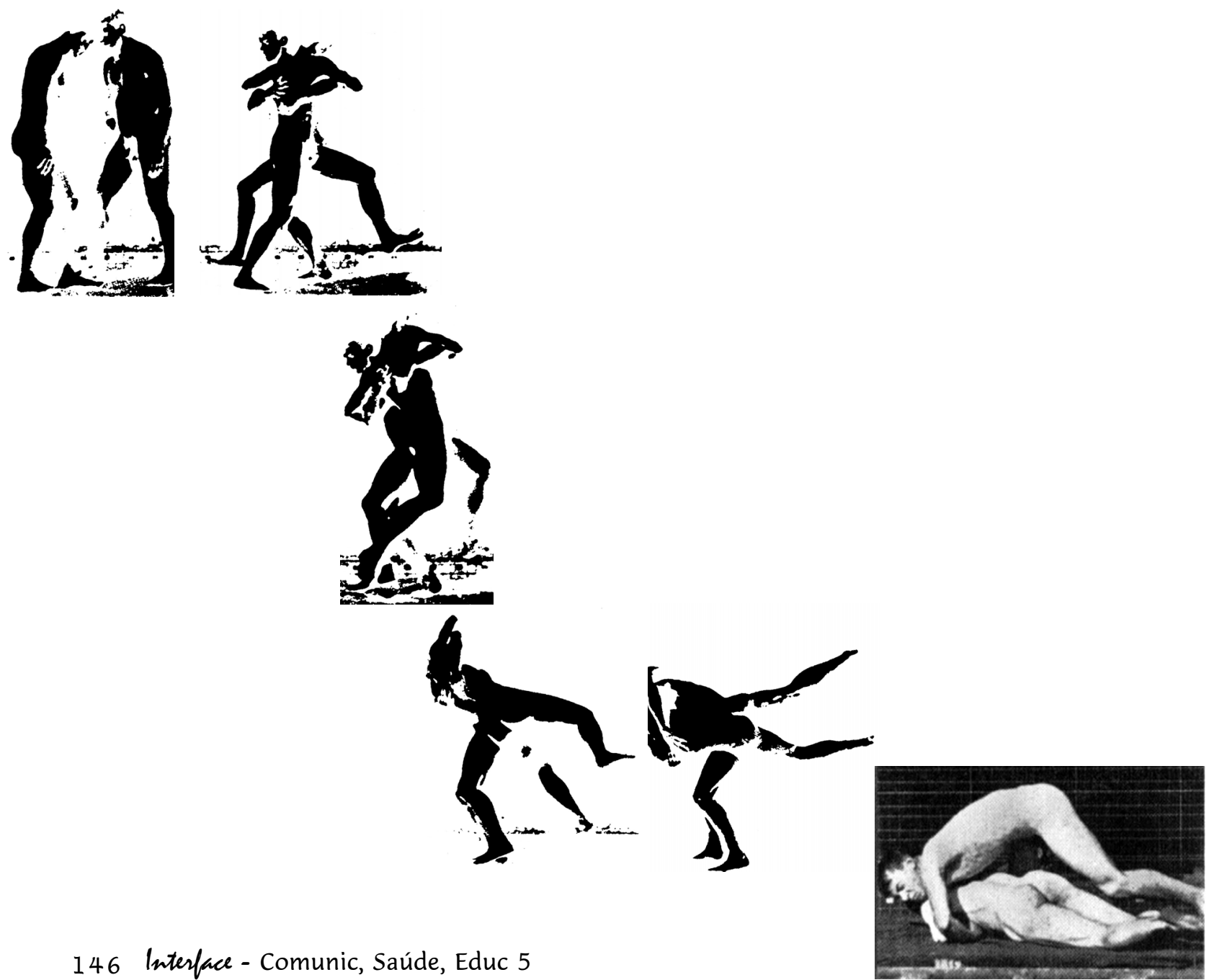